\title{
A Research on Development of Construction Industrialization Based on BIM Technology under the Background of Industry
}

\section{0}

Junjie $\mathrm{Li}^{1 *}$ and Hui Yang ${ }^{1}$

${ }^{1}$ School of Management Engineering, Zhengzhou University, Zhengzhou, Henan, China

${ }^{*}$ Corresponding author: junjie87@126.com

\begin{abstract}
Industry 4.0" and "Made in China 2025", the future strategic plans of the manufacturing industry in Germany and China, are being noted and studied all over the world. In this wave, information and industrialization of production are Construction industry development direction in the future. Based on the introduction of the strategic objectives of "Made in china 2025", a new production pattern of construction industrialization, which is based on BIM technology, are put forward in this paper. Comparative analysis is used in the study of mechanism and development path of the production pattern. The dilemma of construction industrialization confronted at present is illustrated in this paper. Based on the background of implementation of "Made in China 2025", the countermeasures and suggestions of the new production pattern have been proposed.
\end{abstract}

Keyword. Industry 4.0, made in china 2025, construction industrialization, building information modelling, path research

\section{Introduction}

So far, man has experienced three great industrial revolution in history, in which every change has promoted the maximal productivity. At the end of the eighteenth Century, the "Steam Revolution" replaced human labor with steam power, which marked human beings have got into the industrial civilization from the agricultural civilization. At the beginning of twentieth Century, the "Electric Revolution" realized the scale production with electric power. Furthermore, the "Information Revolution" in 1970s improved the automation level of the manufacturing process. In early twenty-first Century, mankind will perform "Industry 4.0 " era with intelligence as its core.

Concept of "Industry 4.0" was formally put forward at the Hannover Industrial Expo in April 2013.It is a common national strategy led by the German government, industry leaders, researchers, associations and trade unions, so as to improve the definition of industry, from the centralized production mode to the basic form of decentralized production and control. It is revolution about internet of things technology, manufacturing services and other technologies that integrate a virtual network with physical entities.

Since the "Industry 4.0" national strategy has been proposed by Germany, other countries put forward their own industrial development strategies, for instance, the US government puts forward the "Industrial Internet Project", France puts forward the strategy of "New Industrial France", the British government puts forward the "British Industrial 2050 Strategy", and Japan puts forward Manufacturing Revival Strategy. Under the background of economic new normality, 
China's manufacturing industry is facing its own drawbacks and international environmental pressure. Premier Li Keqiang proposed "Made in China 2025" plan to reply the challenge of a new round of industrial revolution at the second session of the National People's Congress third conference in March 2015.

\section{From "Made in China 2025" to the construction industrialization}

The essence of "Made in China 2025" is the depth integration between Internet and manufacturing, namely realization of information in the process of manufacture. The fundamental purpose of this strategy is to realize the transformation and upgrading of manufacturing industry that is innovation driven, to promote the manufacturing industry from the low-end level of the global value chain to high-end level, and to use a resource-saving, environment-friendly, innovation driven sustainable development model instead of the original resource-depended, environmental-destructed, labor-intensive and capital-intensive traditional manufacturing industry development model[1]. "Made in China 2025" has always been regarded as China's "Industry 4.0". In June 13, 2016, the fourth round of consultations between Chinese government and German government jointly chaired by Prime Minister Li Keqiang and Prime Minister Angela Dorothea Merkel, the two governments reached a consensus to accelerate the docking of Industry 4.0 and China's industrial upgrading.

Although construction industry and manufacturing industry belong to two different categories, but the two are highly dependent each other. Construction industry can even be regarded as a special kind of manufacturing. As a pillar industry of Chinese national economy, construction industry plays an important role in achieving "Made in China 2025" strategic planning. There are a lot of conjunction points between the development idea of construction industrialization and "Made in China 2025" strategic planning.

Construction industrialization is a kind of the component-prefabricated, the construction-packaging, design-standardized, construction-assembled, management-scientific and operation-informational method, whose objective is reorganizing the construction industry in the way of industrialization so that energies are saved, environment is protected, the value of life cycle is used maximally and the sustainable development can be realized. In order to response to the strategic plan of "Made in China 2025", information has to be realized in construction industry. "Internet Plus" thought should be integrated into industrial production, new manufacture technology should be used to advance intelligent manufacturing of modern architecture, improve comprehensive level of integration, make the construction industry and manufacturing industry develop together, thus while promoting the reform of China's construction industry, grand strategic objectives of "Made in China 2025" can be achieved more swiftly.

\section{Production mode of construction industrialization based on BIM technology}

\subsection{BIM and its characteristics}

Building information modeling(BIM) is a concept that has risen rapidly in the field of construction engineering management. BIM is a technology that describes an engineering project consisting of intelligent facilities with their own data properties and parameter rules, in which each object's appearance and its internal components and features can be displayed in the form of three-dimensional figures.

BIM has five features: visualization, coordination, simulation, optimization, ability of plotting[2]. It can apply information technology to the whole life cycle of any project and enhance collaboration among the participants of the project. In addition, BIM also has a lot of advantages, as shown in Figure 1. The emergence and development of BIM technology has strongly influenced the construction industry. Now software and tools supporting BIM have came out one after another, more and more construction enterprises have entered the field of application of BIM to obtain benefits from the implementation of BIM technology. 


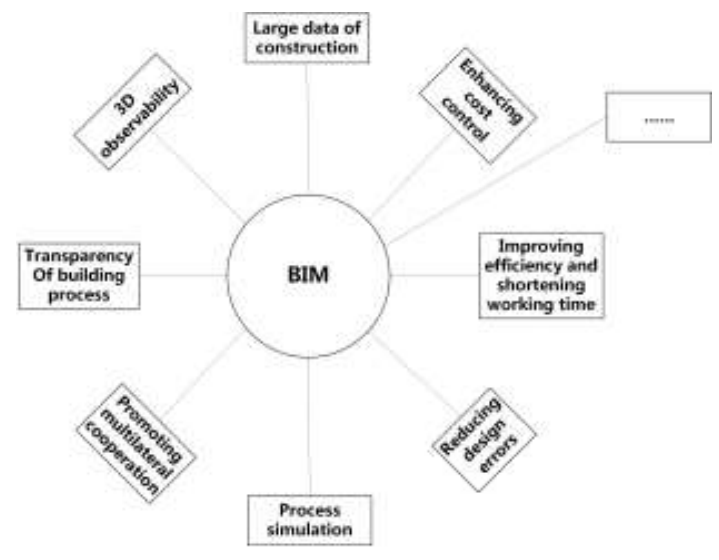

Fig. 1. Advantages of BIM

\subsection{Mechanism analysis of production mode of construction industrialization based BIM technology}

At present, BIM technology is applied to large-scale complex construction projects, but it has not been fully popularized to the design-standardized, construction-assembled construction projects that has huge amount of work. A mechanism of the new production pattern of construction industrialization is established and used in different phases of production of construction industrialization with BIM technology as the core, other engineering technology as auxiliary means.

\subsubsection{Construction logistics management system based on BIM}

In the pre construction preparation phase, BIM technology has some potentials in the material tracking. A real-time observation platform supported by lean thinking and practical experience to benefit supply chain management. It combines the BIM technology with the location based service (LBS). Implementing site management in a virtual construction site can effectively track and monitor workers, equipment and materials, and improve the supply chain management process. Evaluation of environmental impact by the carbon footprint of the supply chain, data and information on the safety and health of workers who is observed are contribute to understanding the situation of the construction site and making the corresponding decision.

\subsubsection{Construction coordination system based on BIM}

In the construction phase, BIM technology and augmented reality (AR) are combined to add digital information to physical components, thus BIM technology can be extended to the construction site and provide virtual information for project manager. Site activities will become much easier to manage, all the information needed for construction activities and model components can be simulated and retrieved in real environment[3]. Real-time cloud services of BIM platform will enable users to receive real-time feedback on their future design decisions and plans through mobile applications such as smart phone applications, etc.. In addition, integrated application of BIM technology and digital processing realizes efficient creation, refined management and accurate delivery of information of construction industrialization[4].

\subsubsection{Facility management system based on BIM}

In the operation phase, the facilities management can be carried out by BIM technology. When BIM technology and GIS are used in information extraction, conversion and download, geometric information can be separated from the related attributes to make the required data integrated effectively. BIM integrated facility management system will not only have 
a great impact on cost efficiency and cost savings, but also improve the value of assets. Moreover, photogrammetry and AR technology as well as BIM can be integrated together to improve the efficiency of facility management[5].

\subsection{Implementation path of production mode of construction industrialization based BIM}

The application of BIM technology is the core of the new pattern of construction industrialization. There are still many obstacles and problems in the development of China's construction industrialization, and the advantages of BIM technology, in order to use BIM technology in production mode of construction industrialization, several following aspects can be choose as "breakthroughs": construction simulation, component testing, component production, information exchange, etc.(As shown in Figure 2)

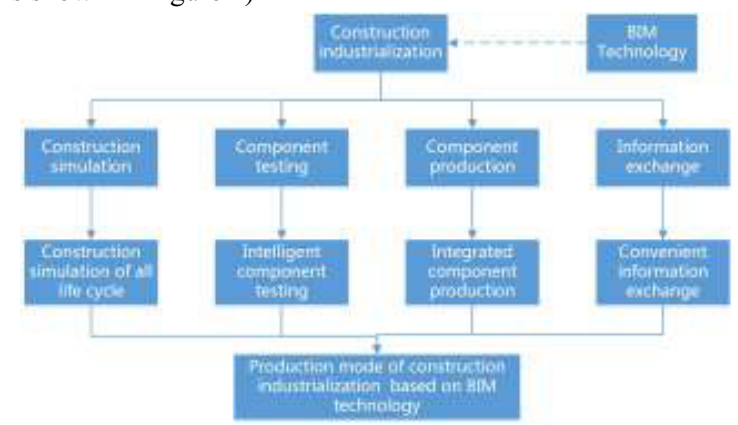

Fig. 2. System frame of development path of production mode of construction industrialization based on BIM

\subsubsection{Carrying out the construction simulation in all life cycle}

Different from the general product components, the volume and weight of buildings' components are generally quite large. It is difficult to transport in long distance[6]. The influences it causes compares to general engineering shows that more negative effects of engineering changes and secondary transportation result from materials produced need to be considered.

For builders, BIM technology is adopted in production of construction industrialization. On the basis of three dimensional visualization function, BIM adds time dimension to it and forms a 4D model. Builders use 4D model to virtually simulate the process of design, construction and operation, which helps them to determine the selection and use of prefabricated components, thus achieves accurate planning and proactive change management. In this way, they can not only ensure quality and safety, but also to reduce waste and improve the overall project performance.

For constructors, BIM technology is used to simulate the 4D model of each phase of projects to examine the appearance, function and situation of construction, and combined with the engineering cost and other information. So they can consider the feasibility and rationality of the project, and then decide whether to invest or not, in order to protect their own interests maximally. In addition, when using real-time cloud services of BIM platform, users are able to view and respond to any construction problems directly from their mobile devices, which is conducive to strengthening the communication between the two sides to prevent unnecessary delays or conflicts may occur in the construction site.

For the investigation unit, data and information of surveying and mapping on pre construction site are transferred to computer, and the data were compared with BIM. They need to calculated deviation for providing basis of further construction process, and keep the design and construction results consistent as far as possible.

\subsubsection{Intelligent test mode of components}

In the construction of construction industrialization, projects need a large number of various types materials or components. The situation that prefabricated components can not match often appear, and these conflicts are more 
complicated and difficult to solve than the problems that occur in concrete casting process. BIM technology can be a good solution to this problem.

BIM technology can be carried in conflict detection and construction analysis of pre construction phase. When projects use BIM software to collision check and build 3D model, the software automatically detects the collision position, and then provides the reasonable position and overlapping sequence of the components. It can quickly test component and record information in short time, and ensure installation can be completed successfully[7].

For the supplier of mechanical, electrical, plumbing (MEP), BIM model provides accurate digital information of service system for MEP contractors and projects. Integration and coordination of MEP system are supported by Autodesk and Solibri and other BIM software, solve that the physical installation conditions are normally not as ideal as the calculation model due to the varying quality of concrete structures. The issue is faced by early practitioners who fabricated system components such as ducts and pipes in factories[8].

\subsubsection{Adopting integrated components production mode}

For suppliers of prefabricated components, BIM model provides very valuable data to support the integration of manufacturer's design, manufacturing, construction, and maintenance process. The data in the BIM model makes the use of prefabricated components in the production process become very convenient, including material ordering, factory logistics, processing, packaging, inventory and transportation to the construction site etc., which accelerates suppliers and cooperation between Party A and Party B, thus saves time and costs.

With BIM and LBS, real-time observation platform supported by lean thinking and practical experience can support following four activities of prefabricated components in construction industrialization: components' design and manufacturing management activity, components transport activity, installation management activity and quality control activity. It not only makes the industrial construction project upgrade quality, but also saves costs and time.

\subsubsection{Promoting convenient information exchange}

In China, design units are independent organizations. They design for owner's requirements such as safety, beauty, economy and environmental protection. However, the situation of construction process, construction management are rarely considered. Design units are lack of communication with builders and supervisors results in design and construction are separated. In addition, all parties involved in construction project are stakeholders, they are facing the contradiction between interests and the overall interests of projects. Therefore information asymmetry between participants in the project also causes a lot of problems. If these problems can't be solved, the high quality and high efficiency of industrial and assembled construction way will be difficult to achieve.

The parametric model provided by BIM saves all information at all life cycle of projects. BIM provides an information platform for engineering projects(As shown in Figure 3). Based on BIM and digital processing of integrated application, as well as the function of tracking of all life cycle of the project, working time, cost, responsibility, materials and suppliers, etc. of each phase of each part are clearly displayed. Participants can obtain information more easily and communicate more efficiently, and avoid conflicts and mistakes caused by poor communication and unclear responsibilities during the process. 


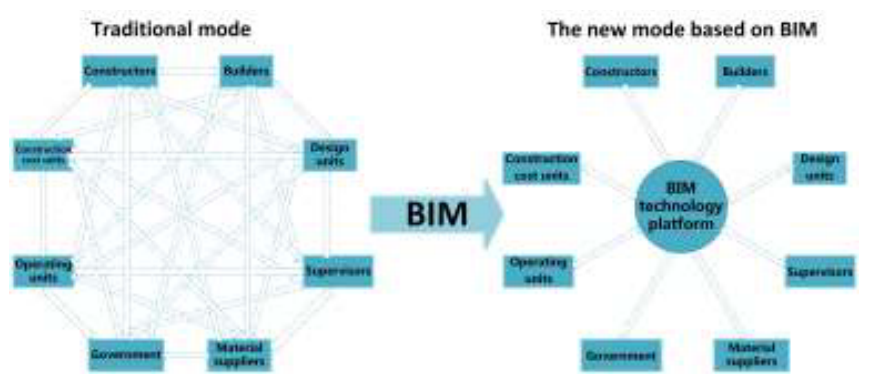

Fig. 3. Difference of information exchange between traditional mode and the new model based on BIM technology

Therefore, the integration of BIM and construction industrialization is utilizing advantages of BIM and construction industrialization, instead of simply combining the concepts. In this way, barriers in the implementation of construction industrialization is broken in China. It is promoting development of construction industrialization, and then enables China's new construction industry realize the goals of high efficiency economy, low carbon environmental protection and sustainable development.

\section{Dilemmas of production mode of China's construction industrialization based BIM technology}

Although BIM has many advantages in promoting construction industrialization, it still faces some dilemmas. This is mainly manifested in the following aspects.

\subsection{The universal degree of construction industrialization and BIM is still low in China}

Nowadays, the proportion of China's construction industrialization projects is still very low. According to a survey, merely $68 \%$ of the designers in China have only heard of BIM, a considerable proportion of designers have never heard, and the designers used BIM are less than 4\%[9]. So, although the mode of construction industrialization based on BIM technology has absolute advantages, it still faces a tremendous challenge.

\subsection{Research fund on BIM technology lacks}

The time is very limited since BIM was introduced into China, degree of domestic research for BIM is small. At present, only several research institutions like China Construction Research Institute, several universities like Tongji University, HUST and several enterprises like Luban, Glodon are committing to the study of BIM applications. That's nowhere near enough. The biggest problem constraints research and development of BIM application is that government's attention and support is far from enough. Due to the insufficient research funds, popularity of research and development of BIM aren't able to come.

\subsection{Enterprises lack a strong incentive to innovate}

Due to the large investment in the early stage of BIM application, for most enterprises especially small and medium sized enterprises, more early they innovate, the return is greater while the investment is greater, which becomes an unfavorable factors blocking enterprise to innovate. Besides, the advantages of BIM is usually applied in all life cycle of building, in which there are a lot of stakeholders. Only few enterprises used BIM technologies can not give full play to its advantages, even it may occur mistakes because of the old and new technology cannot match successfully. State, society and 
construction industry have not advocated and promoted BIM application. Consequently, most of enterprises would rather sacrifice cost and schedule than pour their best to change their production pattern.

\subsection{Lack of construction industrialization standard}

There is the standard parameter of industrialized building at present, but the rules of mandatory implementation haven't established, therefore the standard of construction industrialization has not been unified. However, once BIM is applied in construction industrialization, it's more obvious that interface integration between prefabricated components, in particular, assembled concrete structures depend on the unified standard. Chinese government not only didn't establish relevant standards and provide a strong supervision, but also didn't coordinate and unify entire manufacturing industry, which can not maintain the norms and order of the production of prefabricated components.

\subsection{Relevant laws and regulations are not perfect}

In China, laws and regulations related BIM application are not perfect. Compared to traditional construction mode, the new production pattern has more uncertainty factors. It's possible that various disputes and disputes arise because the standardized contract templates, relevant laws and regulations haven't be provided by Chinese government. What's more, the government's protection for intellectual property rights is so lacking that it doesn't enable to fight against piracy software.

\section{Countermeasures and suggestions on promoting the development of construction industrialization by using BIM technology}

\subsection{Seize opportunities, and take own advantages}

Depends on "Made in China 2025" strategic plan, China should develop construction industrialization under the international background of "Industry 4.0". Construction industry is a special manufacturing industry, and China has one of the largest construction markets all over the world, China should seize opportunities to enable construction industry and real estate industry to become the world's manufacturing power. The goal of the Eighteenth Congress of the Communist Party of China that pushing forward the new urbanization steadily provides a comprehensive implementation platform. It could be used to build a great number of high-efficiency, and high-quality projects, which meets the requirements of the national planning, provides models for reform and accelerate the development of China's construction industrialization.

\subsection{Attach importance to research and development of construction industrialization}

At present, the trouble for scientific research institutions to study BIM and construction industrialization and enterprises to reform is that the preliminary study of BIM and construction industrialization need a large amount of investment. Thus China should increase investment in research and development of advanced technology for scientific research institutions and universities, and train some large enterprises as examples of innovation in the industry that bring a demonstration effect.

\subsection{Improve laws and regulations and construction standards}

To establish a framework for the standardization of construction, Chinese government must improve laws, regulations and construction standards. Avoiding chaos phenomenon without standard of implementing new production pattern, departments should improve the unified standard of construction industrialization and BIM application. In addition, guidelines for the implementation of production and contract templates should be provided, and laws and regulations 
should be improved. In order to strengthen the security, authenticity, reliability and the research of intellectual property rights of BIM technology. Solutions for problems and disputes should be provided to ensure that there must be laws to go by.

\section{References}

1. Yu Donghua, Hu Yanan, Lv Yinan. Research on the path of technological innovation and industrial choice of "Made In China" 2025 under the new industrial revolution. Tianjin Social Sciences, 4 (2015): 98-107.

2. Li Yong,Guan Changsheng. Information management model and strategy of engineering project based on BIM Technology.Journal of Engineering Management, 4 (2012): 17-21.

3. Park, X., Lee, C., Kwon, D. and Wang, X. (2013), “A framework for proactive construction defect management using BIM, augmented reality and ontology-based data collection template", Automation in Construction, Vol. 33, pp. 61-71.

4. Anonymous.BIM+ leading the new direction of the development of BIM. Survey and Design of China, 10 (2015): $27-45$.

5. Hou, L., Wang, X., Wang, J. and Truijens, M. (2014a), “An integration framework of advanced technologies for productivity improvement for LNG mega-projects", Journal of Information Technology in Construction, Vol. 19, pp. 360-382.

6. He Yan, Chen Yan.The present and future of construction industrialization. Engineering Quality, 31.2 (2013): 1-8.

7. Liu Kading, Zhang Yongcheng, Chen Lijuan. Study on the collision analysis of metro station pipeline integrated installation based on BIM technology. Journal of Civil Engineering and Management, 1 (2015): 53-58.

8. Zhang J, Long Y, Lv S, et al. BIM-enabled Modular and Industrialized Construction in China. Procedia Engineering, 2016, 145: 1456-1461.

9. $\mathrm{Mu}$ Xue.Research on the countermeasures of development of BIM in China's construction industry. Shandong Industrial Technology, 24 (2015): 95-96. 